\title{
An Inexpensive Microprint Reader
}

Dr. Ellinger is on the staff of the Subject Cataloging Division, Library of Congress.

A Microcopying process and a microcopy reader which appear interesting in view of the recent discussions of microphotographic methods of documentation ${ }^{1}$ are described in a small book ${ }^{2}$ which, although published in 1940 , was only recently received at the Library of Congress.

The author succeeded in building a camera which allows varying the format of the exposures and controlling their sequence. Thus, one may proceed from photographing a newspaper to photographing a pocket-size book merely by changing the format, while the rate of reduction remains constant. With automatic shutter release and film transport, one hundred pages can be photographed in about fifteen minutes.

As standard size for the film or plate the author recommends the adoption of a format of $9 \times 12 \mathrm{~cm}$. $\left(35 / 8^{\prime \prime} \times 43 / 4^{\prime \prime}\right)$ and a reduction rate of $I: 20$. This allows the reproduction of more than II square feet, corresponding to about 15 newspaper pages or 150 pages of a reference book of customary size, plus extra space for the title, on one piece of cut film.

In the construction of a suitable reading machine, principal consideration was given to achieving a legible image at normal reading distance, and at the same time to saving

${ }^{1}$ Cf. in particular: Rider, Fremont. The Scholar and the Future of the Research Library. New York, Hadham Press, 1944, and the ensuing work of the Microcard Committee which was established to explore the potentialities of the proposals in this work.

' Goebel, Joseph, Schrift, Letter, Mikrokopie. Mainz, Druck der Mainzer Presse, 1940.' space and material. The result is the apparatus shown in the illustration. When not in use, the machine forms a box $4^{\prime \prime} \times 6^{\prime \prime} \times 12^{\prime \prime}$ in size, small enough to be carried in a briefcase. To operate the device, the front is removed and assembled to form a stand. The cover, which has a mirror on the inside, is mounted on it. The film or plate is held by a frame against a translucent screen and can be moved in any direction without losing its proper alignment. A light behind the screen projects the image on the mirror from which it is reflected either on a projection screen or on a piece of white cardboard on the table in front of the reader. Varying degrees of magnification can be achieved simply by moving the mirror. The image can be magnified even beyond the size of the original, a possibility particularly desirable in the case of small print. If it is desired to limit the image to one page or two opposite pages, the undesired parts may be cut off by a mask and the illusion created that the book lies opened on the table. (See illustration.)

Besides being a reading device the apparatus can be put to a number of other uses. If the image is projected on sensitized paper, drawings or copies can be made from it. Brought into proper position, the machine can serve as a music stand. A composition can thus be played from a single sheet of film rather than from voluminous scores. The device can further be used as a projector for any transparencies requiring a magnification from 20 to 50 times. It is able to hold 200 stereoscopic pictures. 
The following are some of the advantages claimed by the inventor as compared with earlier methods of microfilm documentation: (a) the saving of storage space occupied by cut film as compared with that required for cinefilm, and the possibility of filing cut film in card drawers and using it in a vertical file; (b) the possibility of binding or framing cut film and of mailing it in letter envelopes; (c) the greater ease of referring to individual pages than is possible on $35 \mathrm{~mm}$. cinefilm, and the resulting saving of wear and tear; (d) the great resistance of glass to heat and deterioration, when glass plates, in particular the unbreakable kind, are used in lieu of film; (e) the protection which can be given to color film by keeping it between glass; (f) the simple operation, compactness, and low cost of the reading machine, which make it suitable for home use.

A comparison of the method of microreproduction described here with the widely discussed and somewhat similar reproduction on Microcards must, in view of the lack of adequate information on details of operation and cost of manufacture, ${ }^{3}$ be rather hypothetical. Nevertheless, the following differences may be noted.

The Goebel method, in contrast to the production of Microcards, does not require the destruction of the original publication and therefore is suitable for the microreproduction of rare or unique materials; the production of Microcards, since it requires the dissection of two copies of the publication to be processed, at least with the method employed at the present time, is necessarily limited to pamphlets and other expendable materials. With the Goebel method, the process of laying out the pages for photographing is not required. Film

' Reportedly, Philips' Gloeilampenfabrieken in Eindhoven, Holland, manufacture a reading machine built on the principles of the one described here, at a sales price of about $\$ 40$. or glass plates permit greater reduction, and they present, at any rate of reduction, a clearer image than sensitized paper. They also lend themselves readily to color reproductions. The reading device described here appears considerably less expensive

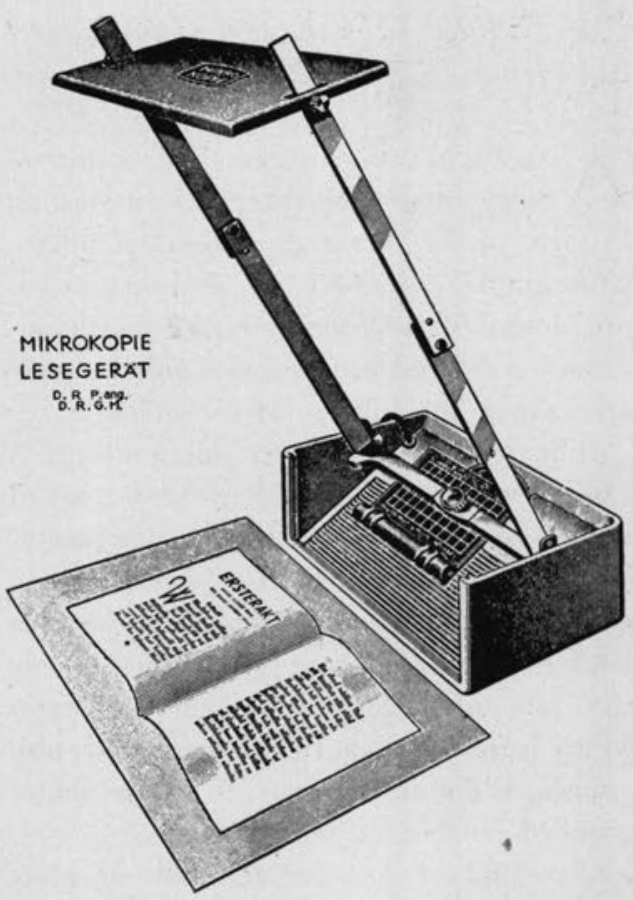

than the reading machines developed thus far for use with Microcards. Because of its adaptability to various uses as mentioned above, the machine may be useful in the library, the lecture room, the home, perhaps even the concert hall. A file of cut film is more durable and suffers less from rough handling than cards. Against these advantages must be held the greater ease with which Microcards can be filed and located, and the lower cost of Microcard stock compared with that of film. However, since all other costs are considerably less in the case of the Goebel method than in that of Microcards, the difference in (Continued on page 45) 
chusetts and Connecticut. It appears that the smaller the library the smaller the resources which can be expected for university development, as well as other governmental services.

\section{Summary}

The following points emerge regarding interstate cooperation in higher education with special reference to the state university libraries which might be involved:

I. The idea of regional cooperation in advanced levels of higher education, while strongly motivated by the desire to continue the practice of racial segregation, has gone beyond that objective. Its application to the general problem of providing university facilities which are not available in large areas of the country has been advocated and is permissible under the compact of February 8, 1948, between fifteen Southern states.

2. Figures for 1944 , with estimates to 1948 , show that about one-half the state university libraries of the country have less than 300,000 volumes. A considerable part of this group, on the basis of a sampling of eleven institutions, offers work up to the Ph.D. degree, and supports one or more graduate professional schools. It is obvious that for existing programs and for expansion these institutions are seriously handicapped with regard to library resources.

3. Enrolments are expected to remain at levels substantially higher than those of prewar years. On a short-term basis a larger proportion of upperclassmen and graduate students can be expected; on a long-term basis the predictions are more doubtful, though the higher general enrolment levels will mean increased demands for all reading materials. This pressure will be felt with special force in those collecting areas which are, and usually have been, given less attention in smaller universities. Such areas include the high-level research literature in a number of subject fields.

4. The twenty-three below-median libraries can be grouped into coherent regional divisions. The Southern states subscribing to the compact of February 8 fall into several groups rather than one. The remaining states, with the addition of a few possessing libraries just above the median size, can be similarly aligned. The institutions which support the libraries are likely to be those which also require extensive additions to their research facilities, and therefore have most to gain from cooperation with others in the same situation.

\section{Microprint Reader}

\section{(Continued from page 38 )}

cost between film and paper is insignificant except in the case of mass reproduction.

Whether in the end film or Microcards will prove more suitable for library use will depend not only on their relative degree of satisfactory performance and the rela- tive cost of production, maintenance, and use, but also upon the manner of distribution of microreproductions and reading machines, and, last but not least, upon their acceptance by the library user as substitutes for the printed page.

\section{Oregon Statutes \\ (Continued from page 40)}

are of such character that release is not practicable, in which case the same amount of time may be allowed at another date. Student recesses in addition to the days above named do not constitute institutional holidays.

\section{Professional Activities}

Administrative Code, K-19. No full-time employee in the Oregon State System of Higher Education or of any of the institutions thereof shall engage in any outside activity which substantially interferes with his regular duties. Prior to acceptance of any employment involving time or honorarium, the individual concerned shall secure the approval of the executive head of the institution. 